\title{
Affect alongside context: Imagining the psychosocial
}

[ B O O K R E VIE W ]

Frosh, Stephen (ed) (2015) Psychosocial imaginaries: Perspectives on temporality, subjectivities and activism. Studies in the Psychosocial series. Hampshire, UK \& New York: Palgrave MacMillan.

There is now an established body of research, often falling under the auspices of "psychosocial studies" and arising mostly from Britain, drawing on social theories alongside psychic theories (especially psychoanalysis) to map subjectivity. This edited book is a wonderful contemporary introduction to this body of psychosocial work, enabling readers to get a flavour of its subject matters, its methods and its theoretical points of departure. What is most striking about this book is the diversity within each of the chapters that nevertheless cohere around a consistent concern with how to understand phenomena from both an "internal" and "external" perspective while always blurring the lines between the two. As such, this book is likely to appeal to theorists and researchers, both student and well-established, from a wide range of disciplines within the humanities.

The book is part of the "Studies in the Psychosocial" book series and its contributors are all located at Birkbeck College, University of London, UK, either in the Department of Psychosocial Studies or as a close affiliate. Psychosocial studies at Birkbeck was founded in 2000 under the headship of Stephen Frosh, who edits the current book, and is certainly known as housing one of the leading groups for the development of psychosocial studies, particular in its more critical form.

\section{Lisa Saville Young} Department of Psychology Rhodes University Grahamstown 
The psychosocial flavour that has developed at Birkbeck is well represented in this edited volume - committed to interdisciplinary work and always wary of the status quo - both uncommon in academia. Birkbeck College is itself an atypical university with an emphasis, since its foundation, on supporting part-time, mature students to gain a higher education while continuing to work. In this sense, it is perhaps no coincidence that it houses a Department of Psychosocial Studies that, as Frosh describes in the introduction to this book, emphasizes the material while insisting that materiality also applies to supposedly "internal" states "associated with subjectivity (and) produced in and by sociality" (p 4). The Department of Psychosocial Studies has been and continues to be particularly influential in the development of a truly transdisciplinary field that takes interiority and exteriority equally seriously without putting them at odds with one another, while always being at odds with itself. By this I mean that, as described in the foreword by Judith Butler, the field of psychosocial studies and the contributors to this book, "form a tightly knit set of considerations on the inseparability of the social and the psychic, but without fusing and reconciling the two terms" ( $p$ vii). At a time where complexity appears to be under attack from all quarters, a field that embraces it is crucial, as indeed is its emphasis on transdisciplinary work at a time where increasingly the boundaries between disciplines are becoming policed.

Newcomers to the field of psychosocial studies will particularly enjoy the foreword and the introduction to the edition by Judith Butler and Stephen Frosh respectively both providing excellent overviews of the field of the psychosocial. Frosh describes how the psychosocial is always concerned with both the psychic and the social and with giving "full weight to their actuality" while also "challenging received wisdom where we think it has settled down too firmly as common sense" ( $p 3$ ). The overview is a helpful introduction to the field for anyone interested in engaging with affect alongside context. In addition, a summary of each chapter is provided in the introductory section of the book which is particularly helpful for the reader to get a sense from the outset of the diverse topics that psychosocial engagement traverses: from time and temporality to the theorizing of the event; from male ageing to Shakespeare's The winter's tale; from digital technologies to citizenship and belonging; from responses to human rights abuses to the legacy of psychoanalysis. It is clear that in these chapters, the authors transverse the disciplinary domains of literature, psychoanalysis, social psychology, sociology, postcolonialism and feminism.

For the purposes of this review I will explore two chapters in more detail: I have chosen two chapters that draw on empirical data due to my own personal interests in the psychosocial and qualitative research, but also because it is in analyzing data that I think the psychosocial framework really demonstrates its usefulness. 
The first chapter that I want to discuss is an excellent demonstration of the centrality of subjective knowing to a psychosocial standpoint. In Sasha Roseneil's chapter on postcolonial citizenship and belonging, she presents data from a moving narrative interview with a British Pakistani woman, Zainab, and provides an extensive analysis of this woman's life history. Her analysis includes a remarkably frank and honest examination of the context of the telling, the fantasies that dominated the researcher's world during the interview and the way in which Zainab's story triggered Sasha Roseneil's autobiographical memories of her own family relationships. It is this subjective knowing that is in particular a hallmark of psychosocial work allowing a combination of "the typical and the commonplace with the singular and the extraordinary" (p 170). It is taking this subjective knowing seriously, while grounding its validity in the text and in the sociocultural context, that enables an engagement with a relational personhood.

The second chapter worth a specific mention is Bruna Seu's chapter on knowing and not knowing in relation to human rights abuses. This chapter is particularly relevant to thinking through South Africans' relationship to knowledge at the moment - whether this relationship be in the context of protest movements in higher education or in relation to government action. What do we do with our knowledge? Does it always guarantee action? How do we understand non-responsiveness to violations? Seu engages with these questions from a psychosocial perspective, drawing on data from interviews with ordinary people about what they feel, think and do when confronted with information about human rights violations. Tracking their responses drawing on social and psychic realities side by side, Seu offers up a view of "troubled subjectivity": "Engaging with this troubled, dynamic and fluid subjectivity reveals the conflict, ambivalence and discomfort in people's reactions to human rights violations .... (generating) an unstable equilibrium that could move either way: either towards more proactive engagement with human rights issues or further entrenchment in passivity and disconnection" ( $p$ 196).

In conclusion, this edited book offers a rich display of the best of contemporary psychosocial thinking. Represented in the book are the ways in which thinking through a psychosocial lens enables one to reclaim the agency that discursive work has been criticised for losing, nevertheless it is an agency that does not reflect a "choosing subject". Rather, from a psychosocial perspective as represented in this book, our unconscious or our defended and yet structuring emotional life is simultaneously expressed and never fully known. It is also not an emotional life that is located "in" individuals, but it is in process between (interpersonal) and around (societal) subjectivities in relation to one another. Employing a psychosocial lens means being responsive to what Butler (2005) describes as our constitution in relationality, "implicated, beholden, derived, sustained by a social world that is beyond us and before us" ( $p$ 64). As such, it is also responsive to accepting the limits of knowability in ourselves and others. As Frosh writes in his 
concluding chapter to this book, this psychosocial attitude leaves us with "a new form of knowledge, which is indeed a mode of subjective destitution and exhaustion, but (from which) it is also possible to notice that something has changed, and to move on with it" ( $p$ 215). Certainly, this book is very likely to leave the reader changed in their ability to understand the value of seeing subjectivity as always already made up of inner and outer life that need to be conceptualised and critiqued both-together.

\section{Reference}

Butler, J (2005) Giving an account of oneself. New York: Fordham University Press. 